\title{
Uniaxially Aligned Poly( $p$-phenylene vinylene) and Carbon Nanofiber Yarns through Electrospinning of a Precursor
}

\author{
Hidenori Okuzaki and $\mathrm{Hu}$ Yan \\ University of Yamanashi \\ Japan
}

\section{Introduction}

Nanofibers made of conducting or semiconducting polymers have been extensively studied from both fundamental and technological aspects to understand their intrinsic electrical and mechanical properties and practical use for elecctromagnetic interference shielding, conducting textiles, and applications to high-sensitive sensors and fast-responsive actuators utilizing their high speccific surface area (Okuzaki, 2006).

Poly( $p$-phenylene vinylene) (PPV) has been paid considerable attention due to its properties of electrical conductivity, electro- or photoluminescence, and non-linear optical response, which have potential applications in electrical and optical devices, such as light-emitting diodes (Burrourghes et al., 1991), solar cells (Sariciftci et al., 1993), and field-effect transistors (Geens et al., 2001). Most of the work with regard to PPV exploits thin coatings or cast films (Okuzaki et al., 1999), while a few reports have been investigated on PPV nanofibers by chemical vapor deposition polymerization with nanoporous templates (Kim \& Jin, 2001). The electrospinning, a simple, rapid, inexpensive, and template-free method, capable of producing submicron to nanometer scale fibers is applied to fabricate nanofibers of conducting polymers, such as sulphuric acid-doped polyaniline (Reneker \& Chun, 1996) or a blend of camphorsulfonic acid-doped polyaniline and poly(ethylene oxide) (MacDiarmid et al., 2001). However, the electrospinning is not applicable to PPV because of its insoluble and infusible nature. Although poly[2-methoxy-5-(2'-ethylhexyloxy)-1,4-phenylenevinylene], an electro-luminescent derivative of PPV, could be electrospun from 1,2-dichloroethane solution as a randomly oriented mesh, the resulting fibers were not uniform exhibiting leaflike or ribbon-like morphology due to the low viscosity limited by the polymer solubility (Madhugiri et al., 2003).

On the other hand, carbon nanofibers have superior mechanical properties, electrical conductivity, and large specific surface area, which are promising for various potential applications in nanocomposites such as electromagnetic interference shielding (Yang et al., 2005), rechargeable batteries (Kim et al., 2006), and supercapacitors (Kim et al., 2004). Currently, the carbon nanofibers are fabricated by a traditional vapor growth (Endo, 1988), arc discharge (Iijima, 1991), laser ablation, and chemical vapor deposition (Ren et al., 1998), but they involve complicated processes and high equipment costs for the fabrication. Reneker et al. fabricated carbon nanofibers by carbonization of electrospun polyacrylonitrile 
(PAN) precursor fibers (Chun et al., 1999). Carbon nanofibers can also be derived from various precursors, such as mesophase-pitch (Park et al., 2003), polybenzimidazol (Kim et al., 2004), and polyimide (Chung et al., 2005). The electrospun fibers are, however, directly deposited on the grounded target as a randomly oriented mesh.

This chapeter deals with a successful fabrication of uniaxially aligned PPV and carbon nanofibers by electrospinning of a soluble precursor and subsequent thermal conversion or carbonization (Fig. 1). The effects of spinning and carbonization conditions on morphology and structure of the resulting nanofiber yarns have been investigated by means of scanning electron microscopy (SEM), Fourier transform infrared (FT-IR), wide-angle X-ray diffraction (WAXD), thermogravimetry (TG), and Raman analyses.

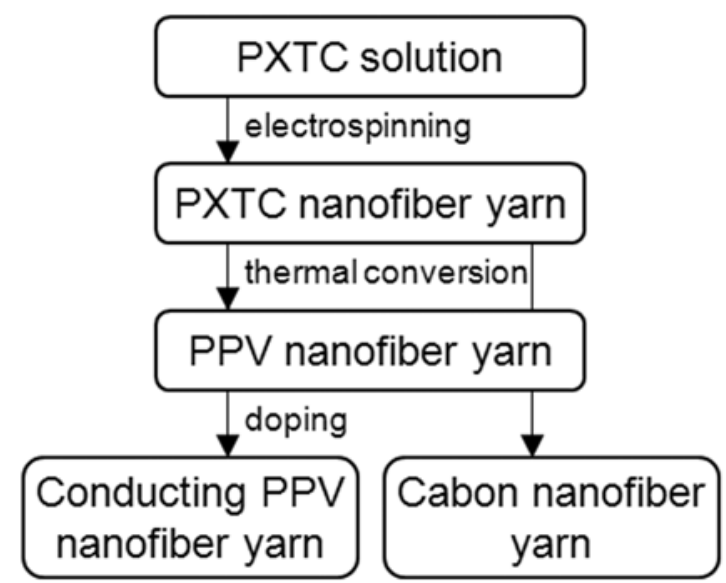

Fig. 1. Flow chart for fabrication of conducting PPV and carbon nanofiber yarns.

\section{Experimental}

Poly(p-xylenetetrahydrothiophenium chloride) (PXTC), a precursor of PPV, was commercially available in the form of $0.25 \%$ aqueous solution from Aldrich Inc. The $M_{\mathrm{w}}$ determined by membrane osmometry was $1.3 \times 10^{5}$, while low-angle laser-light scattering combined with centrifugation yielded $M_{\mathrm{w}}=9.9 \times 10^{5}\left(M_{\mathrm{n}}=5.0 \times 10^{5}, M_{\mathrm{w}} / M_{\mathrm{n}}=2.0\right)$ (Gagnon et al., 2006). About $1 \mathrm{ml}$ of PXTC solution containing different amount of methanol was poured into a glass syringe (12 $\mathrm{mm}$ in diameter) and an electric field was applied to a singlehole spinneret (340 $\mu \mathrm{m}$ in diameter) from a variable high-voltage power supply (Towa Keisoku) capable of applying positive voltages $(E)$ up to $30 \mathrm{kV}$. The electrospun fibers were collected on a grounded flat plate $(10 \times 10 \mathrm{~cm})$ covered with an aluminum foil used as a target where the distance between the needle and the target electrode was $20 \mathrm{~cm}$. The viscosity of the PXTC solution was measured at $30^{\circ} \mathrm{C}$ with a B-type viscometer (VM-10A, CBC Materials). The diameter of yarn was measured with an optical microscope equipped with a video system (InfiniTube, Edmund Optics). The thermogravimetric (TG) analysis was performed with a TG-DTA (2000S, MAC Science) in a temperature range from room temperature to $1000{ }^{\circ} \mathrm{C}$ at a heating rate of $10{ }^{\circ} \mathrm{C} \mathrm{min}-1$ under an argon atmosphere. The PXTC yarns were subsequently converted to PPV yarns by heat treatment at $250{ }^{\circ} \mathrm{C}$ for $12 \mathrm{~h}$ in vacuum. FT-IR spectra was measured with a FTIR-8100 (Shimadzu) and wide-angle X-ray 
diffraction patterns were measured with a RINT (Rigaku). Carbonization of the PXTC yarns was carried out in a quartz tube under vacuum by using an electric furnace (FR100, Yamato). The diameter of thus-carbonized fiber was measured with an FE-SEM (S-4500, Hitachi) and the distribution was evaluated by measuring at least 100 points. The Raman spectra were measured with a laser Raman spectrometer (NRS-2100, JASCO) equipped with an optical microscope. Excitation light from an argon ion laser $(514.5 \mathrm{~nm})$ was focused on the fiber surfaces through the optical microscope.

\section{Results and discussion}

\subsection{Spontaneous formation of PXTC yarns by electrospinning}

Fig. 2 shows optical images of PXTC yarns spontaneously formed by electrospinning at $C=$ $0.1 \%$ and $E=20 \mathrm{kV}$ ). When the applied voltage reaches a critical value, the electrostatic force overcomes the surface tension of the PXTC solution, thereby ejecting a jet from the spinneret.

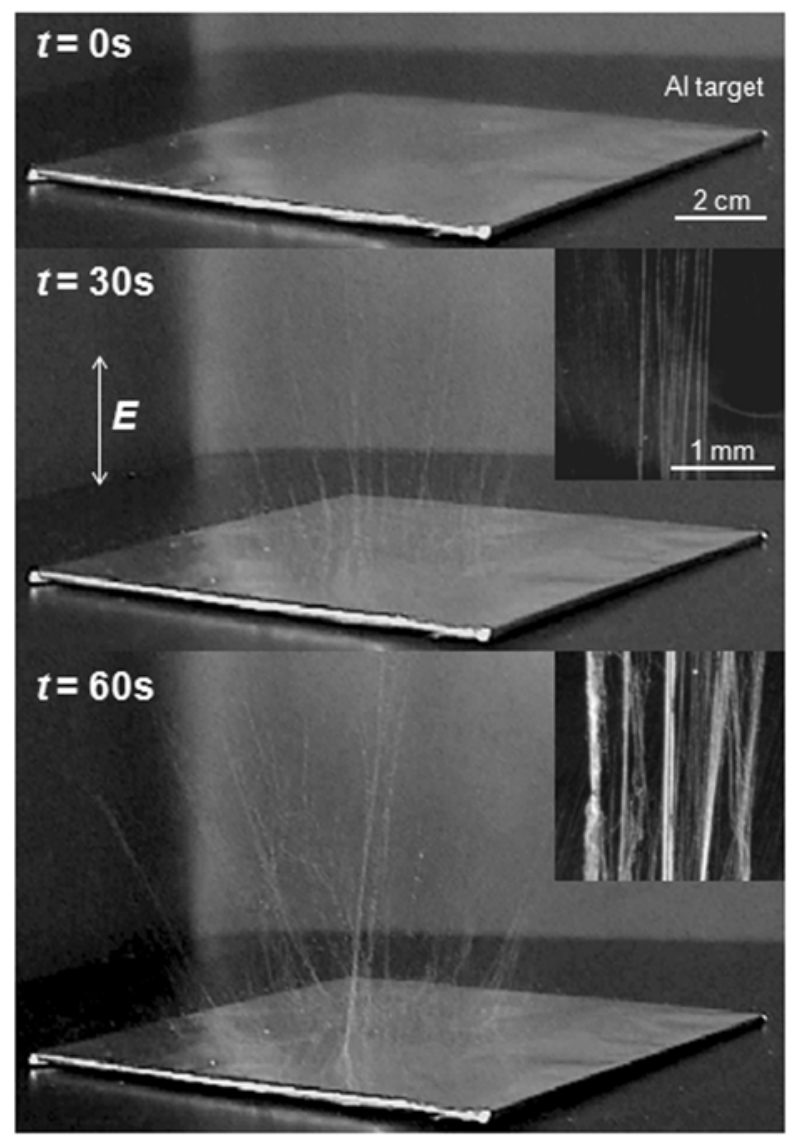

Fig. 2. Spontaneous formation of PXTC yarns by electrospinning at $C=0.1 \%$ and $E=20 \mathrm{kV}$ for 0,30 , and $60 \mathrm{~s}$. 
Since the PXTC chains and solvent molecules bear the same (positive) charge, they repel each other and the droplets become smaller due to the separation while traveling in air during a few milliseconds from the spinneret to the grounded target. Meanwhile, evaporation of solvent molecules takes place rapidly because the separation of droplets produces high surface area to volume. Conventionally electrospun fibers are directly deposited on the grounded target as a randomly oriented mesh due to the bending instability of the highly charged jet. In contrast, the PXTC is electrospun into centimeterslong yarns vertically on the surface of the aluminum target but parallelly to the electric field where an electrostatic attractive force stretches the yarn vertically on the target electrode, leading to a successive upward growth of the yarn. It should be noted that a few yarns get twisted while swinging due to the bending instability of the jet and grow into a thicker yarn. The unusual formation of the yarns can be explained by the ionic conduction of the PXTC (Okuzaki et al., 2006), i. e., the deposited PXTC fibers discharge through polyelectrolyte chains to the ground target, which prefers the following deposition on the electrospun fibers so as to decrease the gap between the fibers and the spinneret. Once a yarn forms by touching the adjacent fibers, the following deposition may preferably occur on the yarn rather than on the individual fibers because of the low electric resistance.

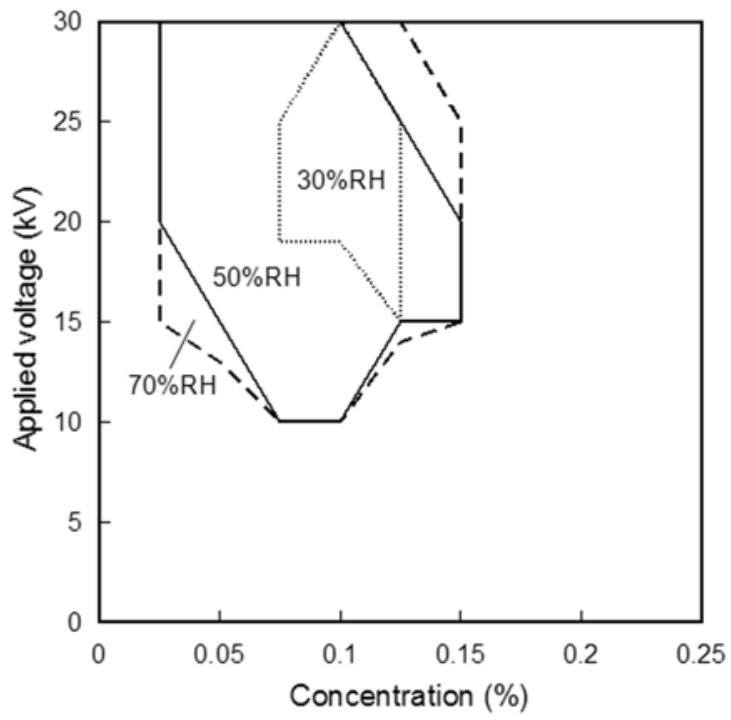

Fig. 3. Effects of applied voltage and concentration on formation of PXTC yarns at various relative humidities.

In order to clarify the mechanism of the yarn formation in more detail, electrospinning was performed at various relative humidities (RHs) and the results were shown in Fig. 3. At 30 $\% \mathrm{RH}$, yarn formed only in a area of $C=0.075 \sim 0.125 \%$ and $E=15 \sim 30 \mathrm{kV}$, while at $70 \% \mathrm{RH}$ the area expanded to $C=0.025 \sim 0.15 \%$ and $E=10 \sim 30 \mathrm{kV}$ (Okuzaki et al., 2008). Here, a rise the ambient humidity from 50 to $70 \% \mathrm{RH}$ increased in the electric current at $E=20 \mathrm{kV}$ from 1.7 to $2.6 \mu \mathrm{A}$ and brought about rapid growth of the yarn. On the other hand, the current was less dependent on the humidity in the absence of the PXTC in the solution (0.39-0.46 $\mu \mathrm{A}$ at $E=20 \mathrm{kV}$ ). This clearly indicates that the ionic conduction of the PXTC crucially 
influences the yarn formation. Indeed, the similar phenomenon was observed for other ionic conducting polyelectrolyte such as poly(acrylic cid). Fig. 4 shows influence of PXTC concentration on average diameter of the yarn, spinning rate, and viscosity of the solution. At $E=20 \mathrm{kV}$, the yarn was formed at $C=0.025 \%-0.15 \%$, while at $C>0.15 \%$, no yarn was formed at $E$ up to $30 \mathrm{kV}$ since the viscosity of the solution $(>8.8 \mathrm{cP})$ was too high to maintain a continuous jet from the spinneret. On the other hand, at $C<0.025 \%$, small droplets of the solution were collected on the surface of the aluminum target due to the low viscosity $(<1.2 \mathrm{cP})$ and surface tension not enough to maintain a stable drop at the spinneret. Thus, methanol crucially increases the volatility of solvent as well as decreases the surface tension, which arises from the fact that dilution with pure water never yields yarn.

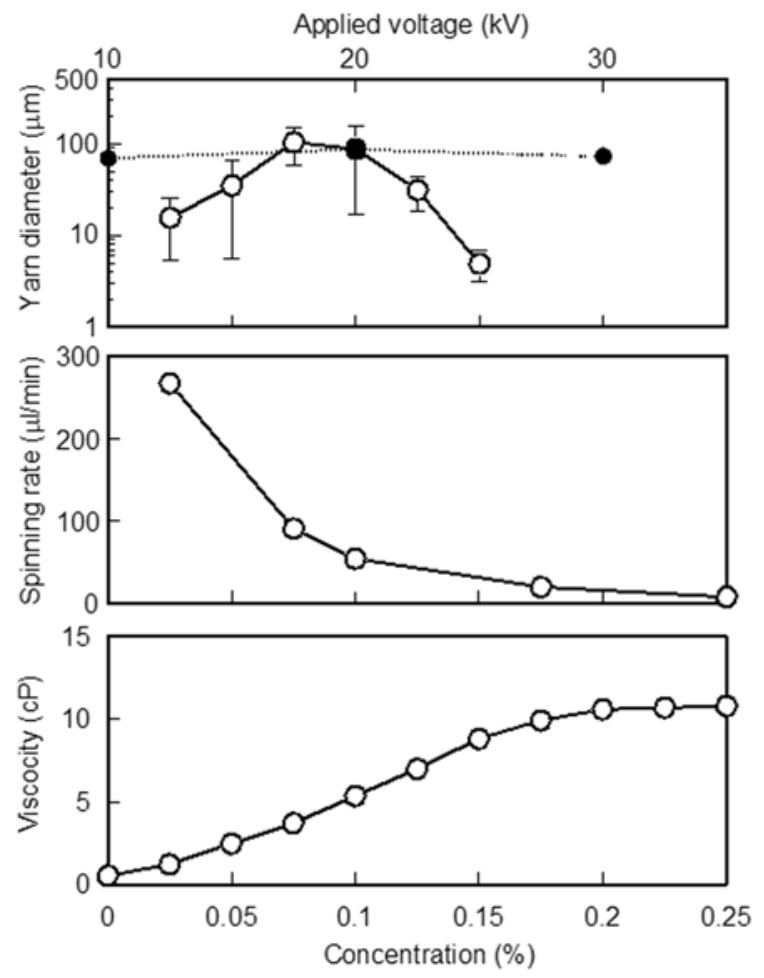

Fig. 4. Dependence of PXTC concentration on average diameter of the yarn and spinning rate at $E=20 \mathrm{kV}$ in $10 \mathrm{~min}$ and viscosity of the solution measured at $30^{\circ} \mathrm{C}$ with a viscometer. Dependence of applied voltage on average diameter of the yarn at $C=0.1 \%$ in $10 \mathrm{~min}$ was also plotted (broken line).

The average diameter of the yarn electrospun at $E=20 \mathrm{kV}$ in 10 min increased from 5 to 100 $\mu \mathrm{m}$ with decreasing of $C$ from $0.15 \%$ to $0.025 \%$. This can be explained by the increase of spinning rate, defined as the average volume of the solution electrospun in $1 \mathrm{~min}$, due to the decrease of viscosity. A further decrease of viscosity, however, yields finer yarns due to the decrease of $C$. The effect of applied voltage on average diameter of the yarn was also demonstrated in Fig. 4 (broken line), where the electrospinning was carried out at a constant 
C of $0.1 \%$ for $10 \mathrm{~min}$. It is found that the average diameter of the yarn is less dependent on the applied voltage and the value is about $100 \mu \mathrm{m}$, where the yarns were as long as the gap between the spinneret and the target electrode $(20 \mathrm{~cm})$. A further electrospinning resulted in a deposition of the droplets on the yarns before the solvent evaporated completely, which allowed the yarns to fall down on the target electrode due to their own weight.

\subsection{Uniaxially aligned PPV nanofiber yarns by thermal conversion of PXTC}

TG curve of the PXTC yarns (solid line) is divided into three major steps in terms of weight loss, as shown in Fig. 5: The first small weight loss at $25-100{ }^{\circ} \mathrm{C}$ is associated with the desorption of moisture, and the second one at $100-250{ }^{\circ} \mathrm{C}$ is due to the elimination of tetrahydrothiophene and hydrochloric acid, corresponding to the conversion to PPV (as shown in the inset) (Okuzaki et al., 1999). The third weight loss at 500-600 ${ }^{\circ} \mathrm{C}$ continuing gradually up to $1000{ }^{\circ} \mathrm{C}$ is due to the carbonation of the PPV that will be discussed later (Ohnishi et al., 1986). The PXTC yarns are subsequently converted to PPV yarns by heat treatment at $250{ }^{\circ} \mathrm{C}$ for $12 \mathrm{~h}$ in vacuum (Okuzaki et al., 1999). About $42 \%$ weight loss of the as-electrospun PXTC yarns in a temperature range of $25-300{ }^{\circ} \mathrm{C}$, decreases to less than $0.01 \%$ after the thermal conversion, demonstrating that the precursor unit is completely converted to PPV.

Fig. 6 shows FT-IR spectra of PXTC yarns electrospun at $C=0.1 \%$ and $E=20 \mathrm{kV}$ and PPV yarns converted at $250{ }^{\circ} \mathrm{C}$ for $12 \mathrm{~h}$ in vacuum. The FT-IR spectrum of the resulting PPV yarns shows a clear peak at $965 \mathrm{~cm}^{-1}$ assigned to the trans-vinylene $\mathrm{C}-\mathrm{H}$ out-of-plane bend, while an absorption peak at $632 \mathrm{~cm}^{-1}$ to the C-S stretch of the PXTC disappeared completely. A clear indication of paracrystalline structure is seen in a wide-angle X-ray diffraction pattern as shown in Fig. 7. The PPV yarns show clear peaks at $2 \theta=20.5^{\circ}(d=4.33 \AA)$ and

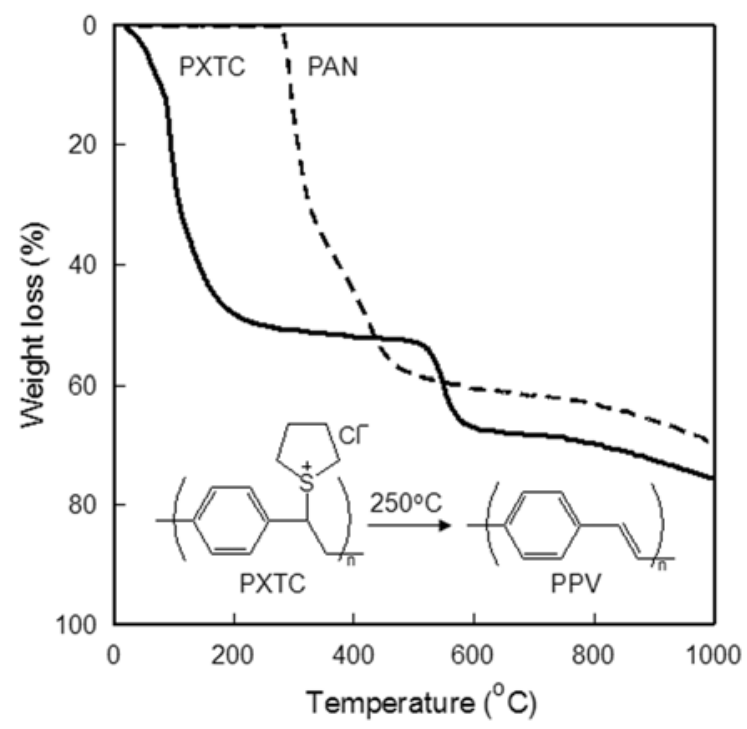

Fig. 5. TG thermograms of the PXTC yarns (solid line) and polyacrylonitrile (PAN: broken line) measured at a heating rate of $10^{\circ} \mathrm{C} \mathrm{min}-1$ under an argon atmosphere. Inset: thermal conversion of PXTC to PPV. 


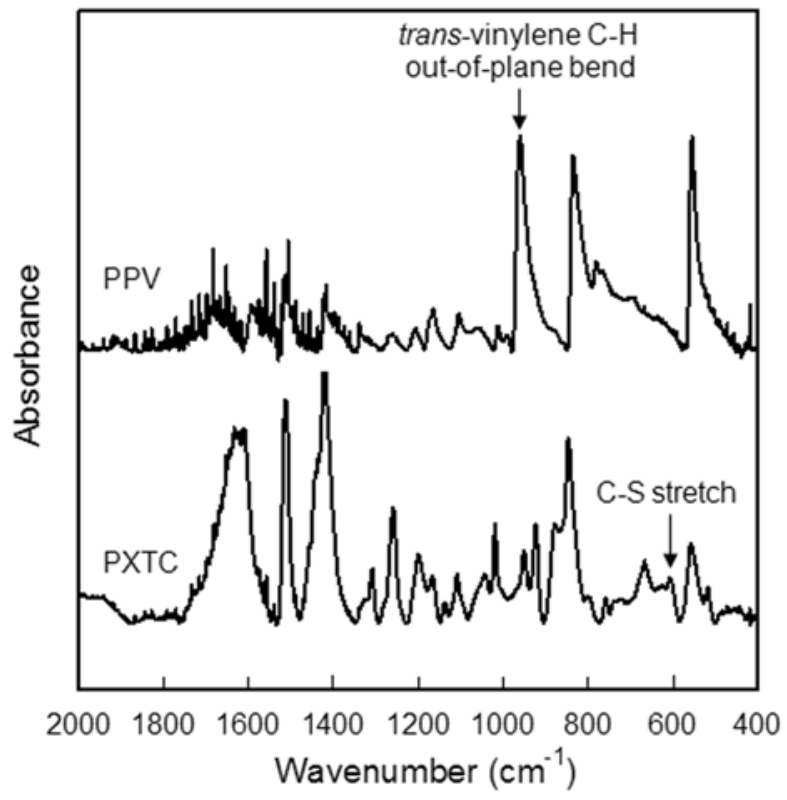

Fig. 6. FT-IR spectra of PXTC yarns electrospun at $C=0.1 \%$ and $E=20 \mathrm{kV}$ and PPV yarns converted at $250^{\circ} \mathrm{C}$ for $12 \mathrm{~h}$ in vacuum.

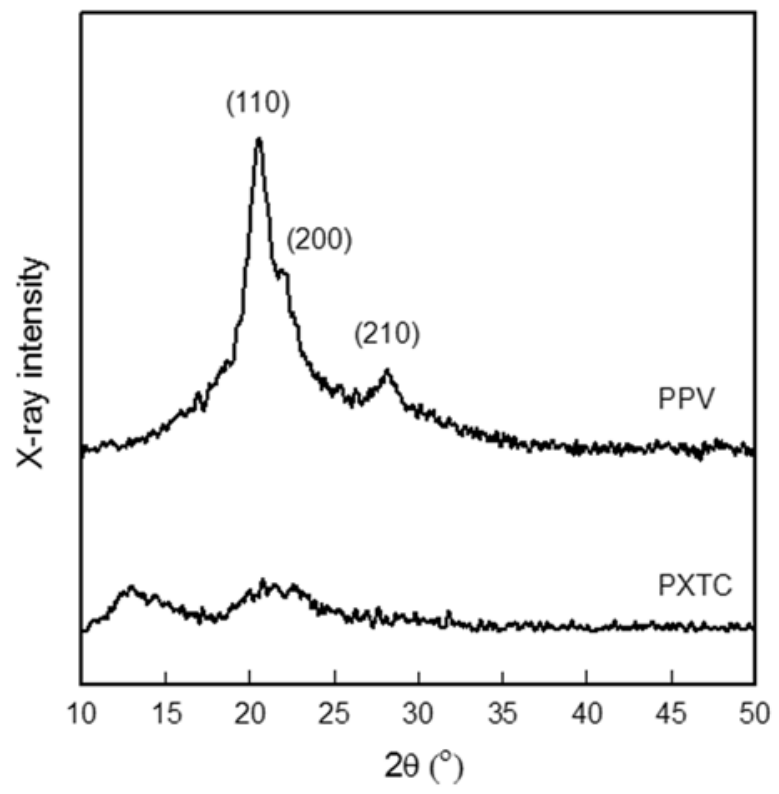

Fig. 7. Wide-angle X-ray diffraction patterns of PXTC yarns electrospun at $C=0.1 \%$ and $E=$ $20 \mathrm{kV}$ and PPV yarns converted at $250{ }^{\circ} \mathrm{C}$ for $12 \mathrm{~h}$ in vacuum. 
$28.2^{\circ}(d=3.16 \AA)$, and a shoulder at $2 \theta=22.0^{\circ}(d=4.03 \AA)$, corresponding to the diffractions from (110), (210), and (200) planes of the monoclinic unit cell of the PPV crystal, respectively (Masse et al., 1989). Since the as-spun PXTC fibers are amorphous, the crystallization will take place during the thermal conversion to PPV. The degree of crystallinity estimated from the WAXD pattern is $c a .45 \%$ and the apparent crystallite size normal to the (210) plane calculated from Scherrer's equation is $75 \AA$. The diffraction patterns of the side and end views of the PPV yarns are substantially the same, indicating no notable orientation of PPV chains on a molecular level.
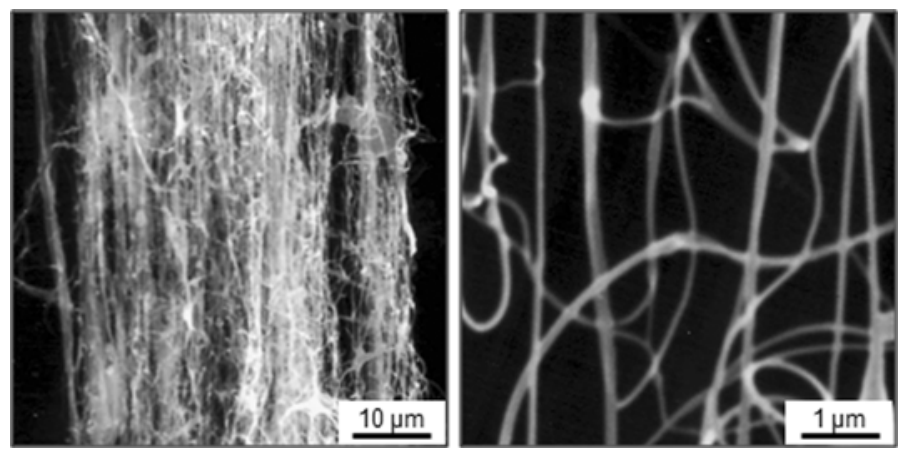

Fig. 8. SEM micrographs of PPV yarn fabricated by thermal conversion of the PXTC yarn elecctrospun at $C=0.1 \%$ and $E=20 \mathrm{kV}$ for $10 \mathrm{~min}$.

It is seen from Fig. 8, a $\mu \mathrm{m}$-thick yarn is composed of numerous PPV nanofibers uniaxially aligned along the axis of the yarn. It is noted that the PPV fibers preserve their morphology even after the elimination reaction. An influence of PXTC concentration on distribution of diameters for the PPV nanofibers is demonstrated in Fig. 9. At $C=0.05 \sim 0.15 \%$, a distribution peak of the fiber diameter locates between $100-200 \mathrm{~nm}$, where more than $50 \%$ of fibers have a diamter less than $200 \mathrm{~nm}$. Particularly, at $C=0.1 \%$, more than $25 \%$ of fibers are finer than $100 \mathrm{~nm}$. In contrast, more than $30 \%$ of fibers are thicker than $500 \mathrm{~nm}$ with a wide distribution at $C=0.025 \%$, which is ascribed to the association or fusion of fibers since the solvents may not evaporate completely due to the low concentration. Furthermore, effects of electric field on distribution of fiber diameter and orientation of the PPV nanofibers were demonstrated in Fig. 10. Although the distribution of fiber diameter is less dependent on the electric field, orientation of the PPV nanofibers along the axis of the yarn is improved as the voltage becomes higher, in which the ratio of fibers having a tilt angle smaller than $10^{\circ}$ increases from $44 \%(E=10 \mathrm{kV})$ to $60 \%(E=30 \mathrm{kV})$. This can be explained by the electrostatic repulsion between positively charged fibers deposited on the yarn ( $\mathrm{Li}$ et al., 2004) and/or explained by stretching the fibers due to the electrostatic force between the spinneret and the yarn in favor of discharging through the yarn, leading to a configuration in parallel alignment (Okuzaki et al., 2008).

\subsection{Conducting PPV nanofiber yarns by acid doping}

The doping is performed by dipping the PPV nanofiber yarns in conc. $\mathrm{H}_{2} \mathrm{SO}_{4}$ at room temperature. After doping, the nanofiber yarns were soaked in a large amount of acetonitrile and dried under vacuum. Fig. 11 shows current-voltage relationship for PPV 

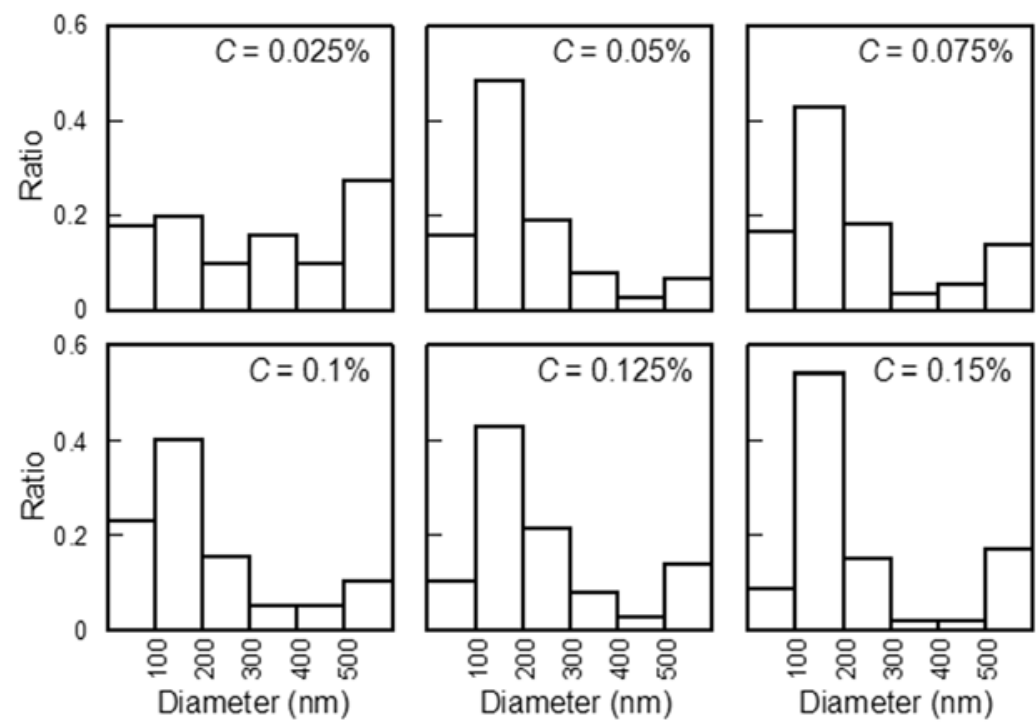

Fig. 9. Dependence of PXTC concentration on distribution of fiber diameter for PPV nanofibers $(E=20 \mathrm{kV})$.
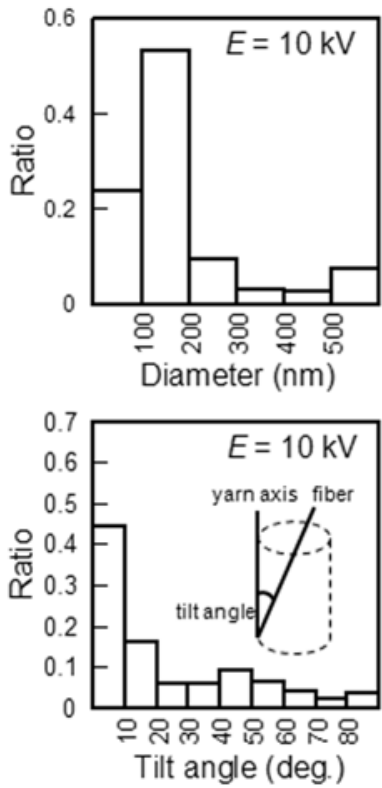

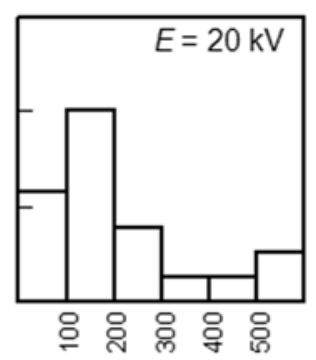

Diameter $(\mathrm{nm})$

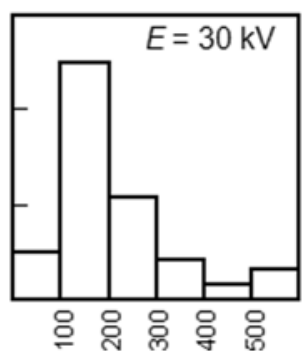

Diameter $(\mathrm{nm})$
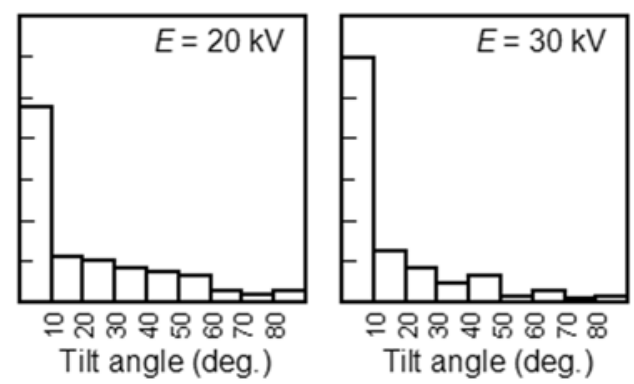

Fig. 10. Dependence of applied voltage on distribution of fiber diameter and orientation of PPV nanofibers along the axis of the yarn $(C=0.1 \%)$. 
and $\mathrm{H}_{2} \mathrm{SO}_{4}$-doped PPV nanofiber yarns measured with a digital multimeter (model 2000, Keithley) by a two-probe method where the nanofiber yarns were placed on two gold electrodes kept at an interval of $2 \mathrm{~mm}$. No detectable current was observed in a voltage range of $-5 \sim+5 \mathrm{~V}$ for the PPV nanofiber yarns, demonstrating that the PPV has extremely low conductivity in the neutral state due to the small carrier density. Upon doping with $\mathrm{H}_{2} \mathrm{SO}_{4}$, the color changed from yellowish brown to black and apparent current flowed through the nanofiber yarns, where the current almost linearly increased in this voltage range and the value attained $1 \sim 2 \mu \mathrm{A}$ at $5 \mathrm{~V}$ (Okuzaki et al., 2008). Although the conductivity of a single nanofiber can not be estimated because mean value of the cross-sectional area in the nanofiber yarns is unknown, the results clearly indicate that the electrical conductivity of the PPV nanofiber yarns increases by doping with $\mathrm{H}_{2} \mathrm{SO}_{4}$.

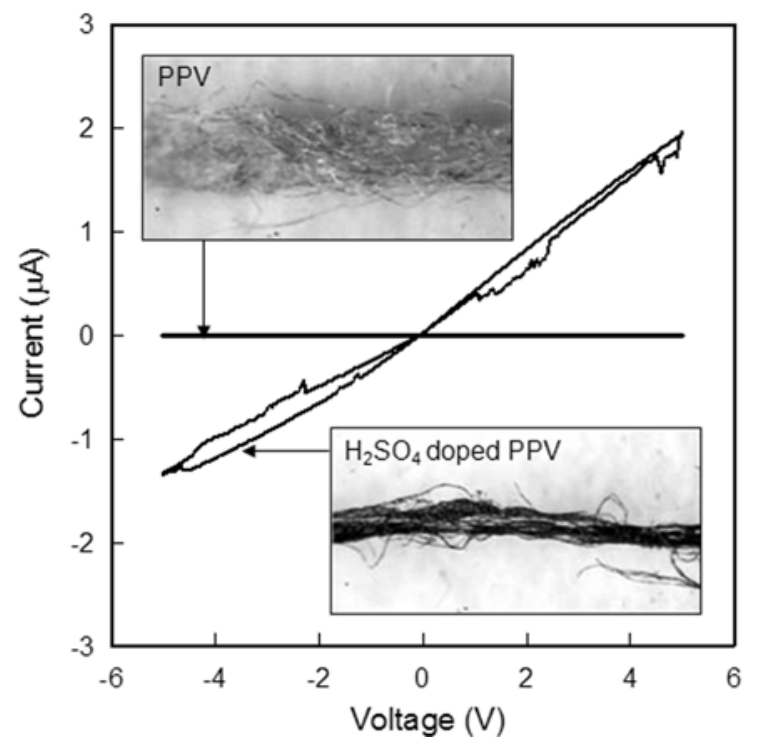

Fig. 11. Current-voltage relationship for PPV and $\mathrm{H}_{2} \mathrm{SO}_{4}$-doped PPV nanofiber yarns.
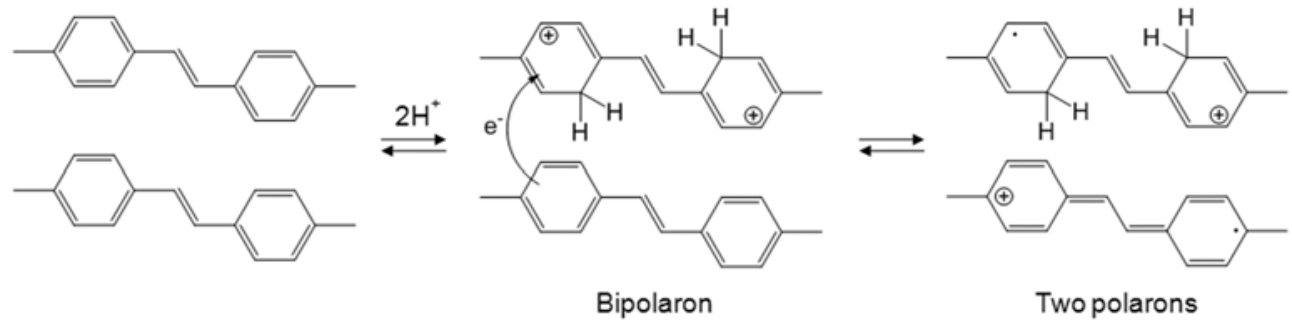

Fig. 12. Schematic illustration of proposed doping mechanism of PPV.

This can be explained by oxidation of PPV to produce charge carriers where anions are intercalated between polymer chains as counter ions (Okuzaki et al., 2005). However, the doping of PPV with protonic acids has not been fully understood yet (Ahlskog et al., 1997). Han et al. have found that non-oxidizing protonic acids can be effective dopants for a wide 
range of conjugated polymers (Han \& Elsenbaumer, 1989). The mechanism of protonic acid doping appears to involve direct protonation of the polymer backbone followed by an internal redox process that gives polarons as the predominant charge defects, similarly to polyaniline (Chiang \& MacDiarmid, 1986).

\subsection{Uniaxially aligned carbon nanofibers by thermal conversion of PXTC}

It is seen from the TG curve as shown in Fig. 5, the third weight loss at $500-600{ }^{\circ} \mathrm{C}$ continuing gradually up to $1000{ }^{\circ} \mathrm{C}$ is due to the carbonization of the PPV (Ohnshi et al., 1986). As a comparison, the TG curve of PAN, a typical precursor of carbon fiber (broken line), shows a significant weight loss of about $40 \%$ between 300 and $500{ }^{\circ} \mathrm{C}$. This corresponds to the carbonation, involving dehydrogenation, cyclization, and polymerization of nitrile groups, and then losing noncarbon elements, such as $\mathrm{HCN}, \mathrm{NH}$, and $\mathrm{H}$, in the form of volatile gases. As a result, the carbon yield for the PXTC was $25 \%$ at $1000{ }^{\circ} \mathrm{C}$, which was somewhat smaller than that for the PAN $(30 \%)$.
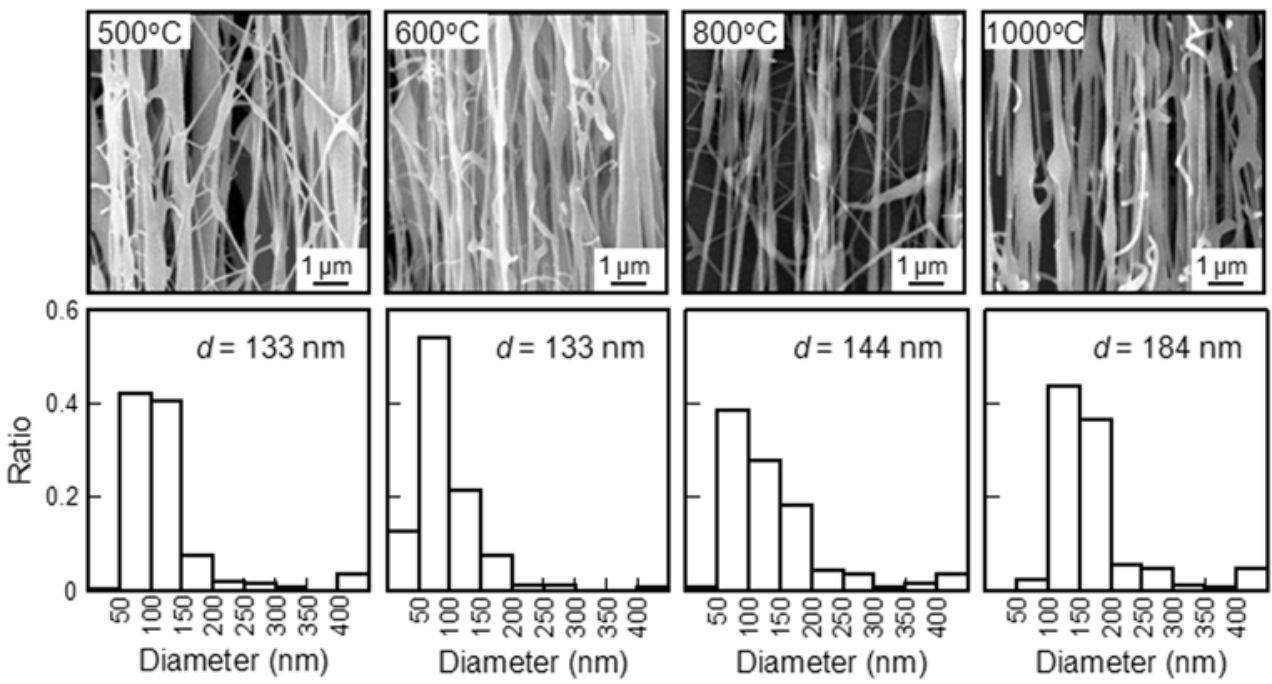

Fig. 13. SEM micrographs and distribution of fiber diameter for various nanofiber yarns thermally treated at various temperatures.

Fig. 13 shows SEM micrographs and distribution of fiber diameter for the PXTC yarns thermally treated at various temperatures. Although we failed to measure SEM micrographs of the as-electrospun PXTC yarns owing to the elimination of tetrahydrothiophene and hydrochloric acid under the radiation of an electron beam, it can be considered that the fiber diameter decreases during the thermal conversion to PPV based on the fact that nearly $50 \%$ of weight is lost up to $250{ }^{\circ} \mathrm{C}$ (Fig. 5). Agend et al. (2007) fabricated carbon nanofibers by electrospinning of PAN from DMF solution and subsequent carbonization and found that average diameter of PAN nanofibers decreased from 149 to $109 \mathrm{~nm}$ by carbonization at 1100 ${ }^{\circ} \mathrm{C}$. It should be emphasized in Fig. 13 that the fibers preserve their morphology with average diameters $d=133-184 \mathrm{~nm}$. Interestingly, the nanofibers were uniaxially aligned along the axis of the yarn, similarly as observed in PPV nanofibers where about $70 \%$ of 
nanofibers in the yarn had a tilt angle less than $30^{\circ}$ (Okuzaki et al., 2008). Furthermore, there was no notable change in the morphological structure and the distribution of fiber diameter even at temperatures higher than $500-600{ }^{\circ} \mathrm{C}$ of the third weight loss where the carbonization of the PPV occurs.

Raman spectroscopy is one of the most sensitive tools for providing information on the crystalline structure of carbon fibers. The highly ordered carbon such as a single hexagonal crystal graphite shows a strong peak at $1582 \mathrm{~cm}^{-1}$ (G band) from in-plane modes with $E_{2 \mathrm{~g}}$ symmetry, while the disordered carbon due to imperfection or lack of hexagonal symmetry shows a broad peak at $1360 \mathrm{~cm}^{-1}$ (D band) (Kim et al., 2004). A clear evidence of the structural change caused by the carbonization is demonstrated in Fig. 14. Two peaks at around 1580 and $1360 \mathrm{~cm}^{-1}$, assigned to $\mathrm{G}$ and D bands, respectively, evidently appear in the Raman spectra for the nanofiber yarns thermally treated at temperatures higher than $600{ }^{\circ} \mathrm{C}$, indicating practical transformation of disordered carbon into graphitic structure in the carbonization process. It notes that the carbonization took place without melting process accompanying the third weight loss at 500-600 ${ }^{\circ} \mathrm{C}$, suggesting that the PPV is intermolecularly condensed to form more compact structures by removal of hydrogen and aromatization (Ohnishi et al., 1986) as shown in Fig. 15, similarly to carbonization of poly( $p$ phenylene) (Fitzer et al., 1971).

Lespade et al. (1984) identified four graphitization indices: (i) the wavenumber of the G band, (ii) the band width of the G band, (iii) the intensity ratio of the D and G bands, and (iv) the band width of the second order phonon. Especially, the intensity ratio of the D and $G$ bands is one of the most important parameters characterizing not only the degree of graphitization but also defects in the carbonaceous materials. Using a mixed GaussianLorentzian curve-fitting procedure, the ratio of the integrated intensity $(R)$ of the $\mathrm{D}\left(I_{\mathrm{D}}\right)$ and G bands $\left(I_{\mathrm{G}}\right)$ is calculated as

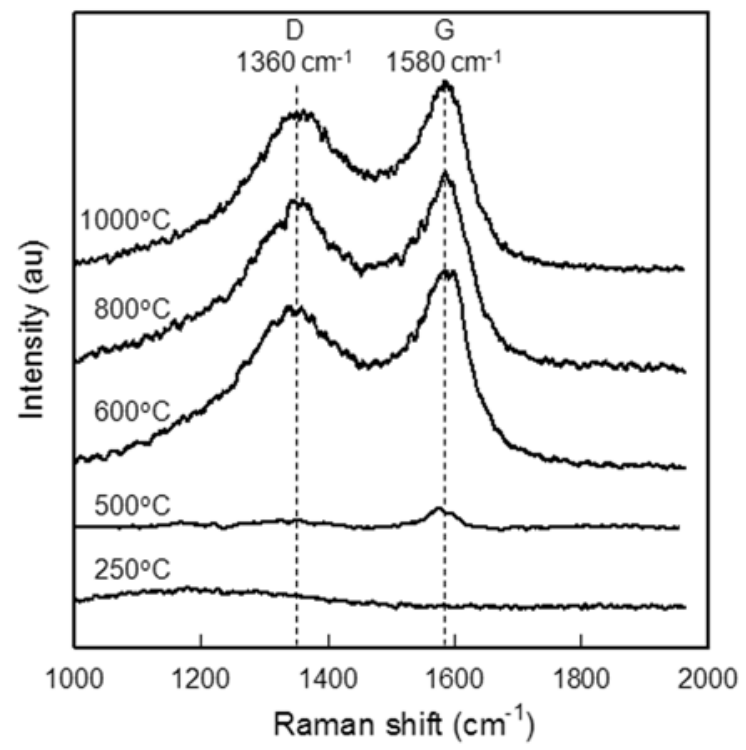

Fig. 14. Raman spectra of various nanofiber yarns thermally treated at various temperatures. 


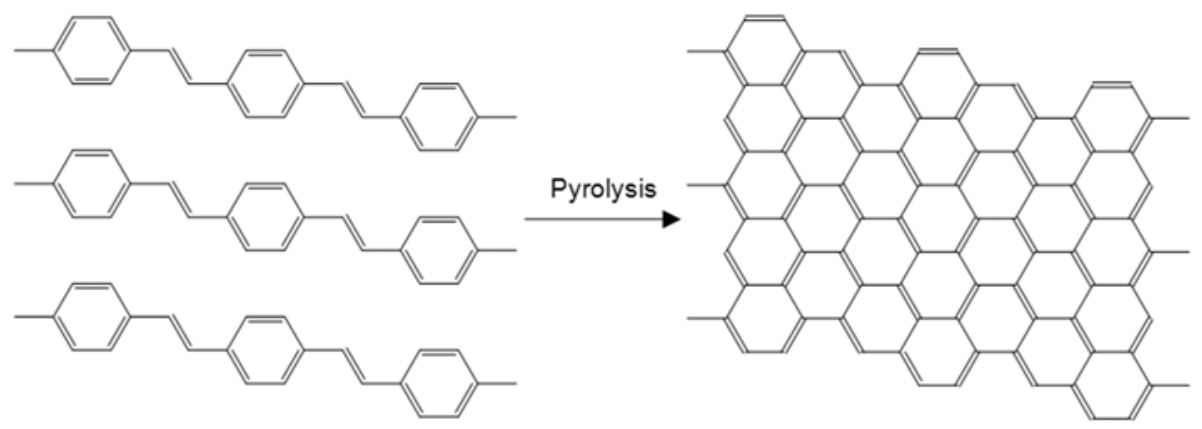

Fig. 15. Schematic illustration of pyrolysis of PPV.

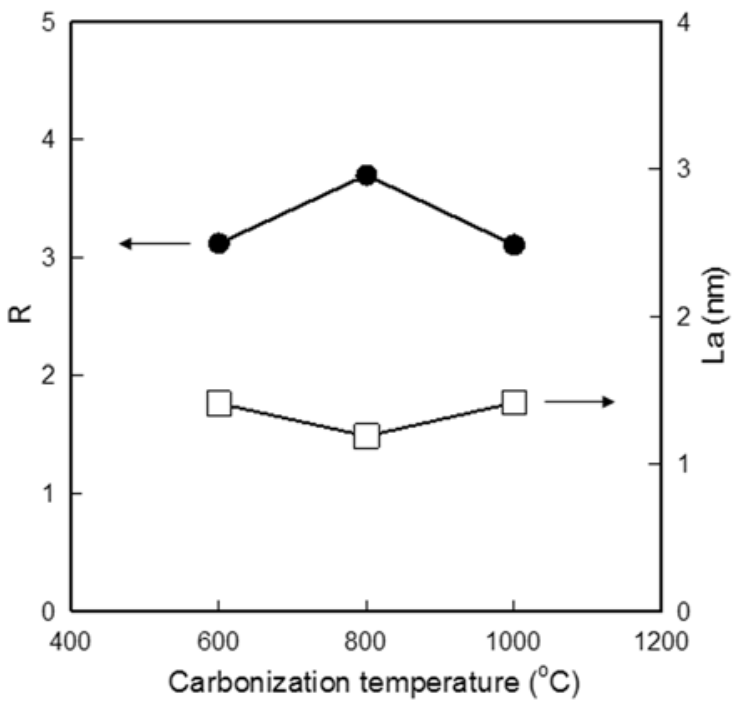

Fig. 16. Dependence of carbonization temperature on $R$ and $L_{a}$ values for various carbon nanofiber yarns.

$$
\mathrm{R}=\mathrm{I}_{\mathrm{D}} / \mathrm{I}_{\mathrm{G}}
$$

The $R$ is also sensitive to the concentration of graphite edge planes and/or crystal boundaries relative to standard graphite planes. Knight and White (1989) investigated the relation between $R$ and the graphitic crystallite size $\left(L_{\mathrm{a}}\right)$ for Tuinstra and Koenig's original data plus such additional data from the literature (Tuinstra \& Koenig, 1970). They found the inverse relation between $R$ and $L_{\mathrm{a}}$ and developed an empirical formula as

$$
\mathrm{L}_{\mathrm{a}}=4.4 / \mathrm{R}
$$

In Fig. 16, the values of $R$ and $L_{\mathrm{a}}$ for the nanofibers carbonized at $600-1000{ }^{\circ} \mathrm{C}$ are $3.1-3.7$ and 1.2-1.4 nm, respectively, which are similar to those of the PAN-derived carbon nanofibers (Wang et al., 2003). Since the Raman spectra do not change at the carbonization temperatures between 600 and $1000{ }^{\circ} \mathrm{C}$, the variation of the $R$ value is considered to be 
within the experimental error. Assuming that the $I_{\mathrm{G}}$ and $I_{\mathrm{D}}$ are proportional to the number of the scattering ordered and disordered $\mathrm{sp}^{2}$ bonding carbon atoms, their molar fractions $X_{\mathrm{G}}$ and $X_{\mathrm{D}}$ can be defined as follows.

$$
\begin{aligned}
& X_{G}=I_{G} /\left(I_{G}+I_{D}\right)=1 /(1+R) \\
& X_{D}=I_{D} /\left(I_{G}+I_{D}\right)=R /(1+R)
\end{aligned}
$$

From equations (2)-(4), the higher the degree of graphitization, the higher the $X_{\mathrm{G}}$ and $L_{\mathrm{a}}$, but the lower the $X_{\mathrm{D}}$ and $R$. The values of $X_{\mathrm{G}}$ and $X_{\mathrm{D}}$ were calculated as $0.21-0.24$ and $0.76-0.79$ for the resulting carbon nanofiber yarns, respectively.

\section{Conclusion}

Unlike conventional electrospun polymer fibers deposited on a target electrode as a randomly oriented mesh, PXTC was electrospun into centimeters-long yarns vertically on the surface of the electrode but parallel to the electric field. The formation of the yarn was strongly influenced by the concentration, applied voltage, and relative humidity. The subsequent thermal conversion of thus-electrospun PXTC yarns was carried out at $250{ }^{\circ} \mathrm{C}$ for $12 \mathrm{~h}$ in vacuum and resulted in the uniaxially aligned PPV nanofibers with an average diameter of $150 \mathrm{~nm}$. The applied voltage enhanced orientation of PPV nanofibers along the axis of the yarn, while the distribution of fiber diameter was less dependent on the applied voltage. WAXD analysis indicated that the PPV nanofibers exhibited paracrystalline structure with crystallinity and crystallite size of $45 \%$ and $75 \AA$, respectively. Furthermore, doping with sulfuric acid changed the color from yellowish brown to black and brought about a significant increase in the electrical conductivity of the PPV nanofiber yarn. The uniaxially aligned carbon nanofibers with average diameters of 133-184 nm were successfully fabricated by carbonization of the PXTC nanofiber yarns. The graphitic crystallite size and the molar fraction of the ordered $\mathrm{sp}^{2}$ bonding carbon atoms in the resulting carbon nanofiber yarns carbonized at $60-1000{ }^{\circ} \mathrm{C}$ were $1.2-1.4 \mathrm{~nm}$ and $0.21-0.24$, respectively. Thus, we succeeded in fabricating uniaxially aligned semiconducting, conducting, and carbon nanofiber yarns by electrospinning and subsequent thermal conversion or carbonization of PXTC, which would open up a new field of applications in organic nanoelectronics such as elecctromagnetic interference shielding, conducting textiles, and high-sensitive sensors and fast-responsive actuators utilizing their high speccific surface area.

\section{References}

Agend, F.; Naderi, N. \& Alamdari, R. F. (2007). Fabrication and electrical characterization of electrospun polyacrylonitrile-derived carbon nanofibers, J. Appl. Polym. Sci., 106, 255-259.

Ahlskog, M.; Reghu, M.; Noguchi, T. \& Ohnishi, T. (1997). Doping and conductivity studies on poly(p-phenylene vinylene), Synth. Met., 89, 11-15.

Burrourghes, J. H.; Bradley, D. D. C.; Brown, A. R.; Marks, R. N.; Mackay, K.; Friend, R. H.; Burns, P. L. \& Holmes, B. (1991). Light-emitting diodes based on conjugated polymers, Nature, 347, 539-541. 
Chiang, J. C. \& MacDiarmid, A. G. (1986). 'Polyaniline': Protonic acid doping of the emeraldine form to the metallic regime, Synth. Met., 13, 193-205.

Chun, I.; Reneker, D. H.; Fong, H.; Fang, X.; Deitzel, J.; Beck-Tan, N. \& Kearns, K. (1999). Carbon nanofibers from polyacrylonitrile and mesophase pitch, J. Adv. Mater., 31, $36-41$.

Chung, G. S.; Jo, S. M. \& Kim, B. C. (2005). Properties of carbon nanofibers prepared from electrospun polyimide, J. Appl. Polym. Sci., 97, 165-170.

Endo, M. (1988). Grow carbon fibers in the vapor phase, CHEMTECH, 18, 568-576.

Fitzer, E.; Mueller, K. \& Schaefer, W. (1971). The chemistry of the pyrolytic conversion of organica compounds to carbon, Chem. Phys. Carbon, 7, 237-383.

Gagnon, D. R.; Capistran, J. D.; Karasz, F. E.; Lenz, R. W. \& Antoun, S. (1987). Synthesis, doping, and electrical conductivity of high molecular weight poly(p-phenylene vinylene), Polymer, 28, 567-573.

Geens, W.; Tsamouras, D.; Poortmans, J. \& Hadziioannou, G. (2001). Field-effect mobilities in spin-cast and vacuum-deposited PPV-type pentamers, Synth. Met., 122, 191-194.

Han, C. C. \& Elsenbaumer, R. L. (1989). Protonic acids: Generally applicable dopants for conducting polymers, Synth. Met., 30, 123-131.

Iijima, S. (1991), Helical microtubules of graphitic carbon, Nature (London), 354, 56-58.

Kim, K. \& Jin, J.-I. (2001). Preparation of PPV nanotubes and nanorods and carbonized products derived therefrom, Nano Lett., 1, 631-636.

Kim, C.; Kim, Y. J. \& Kim, Y. A. (2004). Fabrication and structural characterization of electrospun polybenzimidazol-derived carbon nanofiber by graphitization, Solid State Commun., 132, 567-571.

Kim, C. K.; Park, S. H.; Lee, W. J.; Yang, K. S. (2004). Characteristics of supercapaitor electrodes of PBI-based carbon nanofiber web prepared by electrospinning, Electrochim. Acta, 50, 877-881.

Kim, C.; Park, S. H.; Cho, J. I.; Lee, D. Y.; Park, T. J.; Lee, W. J. \& Yang, K. S. (2004). Raman spectroscopic evaluation of polyacrylonitrile-based carbon nanofibers prepared by electrospinning, J. Raman Spectrosc., 35, 928-933.

Kim, C.; Yang, K. S.; Kojima, M.; Yoshida, K.; Kim, Y. J.; Kim, Y. A. \& Endo, M. (2006). Fabrication of electrospinning-derived carbon nanofiber webs for the anode material of lithium-ion secondary batteries, Adv. Funct. Mater., 16, 2393-2397.

Knight, D. S. \& White, W. B. (1989). Characterization of diamond films by Raman spectroscopy, J. Mater. Res., 4, 385-393.

Lespade, P.; Marchand, A.; Couzi, M. \& Cruege, F. (1984). Caracterisation de materiaux carbones par microspectrometrie Raman, Carbon, 22, 375-385.

Li, D.; Wang, Y. \& Xia, Y. (2004). Electrospinning nanofibers as uniaxially aligned arrays and layer-by-layer stached films, Adv. Mater., 16, 361-366.

MacDiarmid, A. G.; E. Jones, Jr., W.; Norris, I. D.; Gao, J.; Johnson, Jr., A. T.; Pinto, N. J.; Hone, J.; Han, B.; Ko, F. K.; Okuzaki, H. \& Llaguno, M. (2001). Electrostaticallygenerated nanofibers of electronic polymers, Synth. Met., 119, 27-30.

Madhugiri, S.; Dalton, A.; Gutierrez, J.; Ferraris, J. P.; Balkus K. J. Jr. (2003). Electrospun MEH-PPV/SBA-15 composite nanofibers using a dual syringe method, J. Am. Chem. Soc., 125, 14531-14538. 
Masse, M. A.; Schlenoff, J. B.; Karasz, F. E. \& Thomas, E. L. (1989). Crystalline phases of electrically conductive poly(p-phenylene vinylene), J. Polym. Sci., Polym. Phys., 27, 2045-2059.

Ohnishi, T.; Murase, I.; Noguchi, T. \& Hirooka, M. (1986). Highly conductive graphite film prepared from pyrolysis of poly(p-phenylene vinylene), Synth. Met., 14, 207-213.

Okuzaki, H.; Ikeda, N.; Kubota, I. \& Kunugi, T. (1999). Mechanical properties and structure of poly(p-phenylenevinylene) films prepared by the zone-reaction method, Macromolecules, 32, 5606-5612.

Okuzaki, H.; Hirata, Y. \& Kunugi, T. (1999). Mechanical properties and structure of zonedrawn poly( $p$-phenylene vinylene) films, Polymer, 40, 2625-2629.

Okuzaki, H.; Ikeda, N.; Kubota, I. \& Takahashi, T. (2005). Zone-reacted poly(p-phenylene vinylene) films. Changes in mechsnical properties and microstructure by acid doping, Synth. Met., 153, 165-168.

Okuzaki, H.; Takahashi. T.; Miyajima, N.; Suzuki, Y. \& Kuwabara, T. (2006). Spontaneous formation of poly(p-phenylene vinylene) nanofiber yarns through electrospinning of a precursor, Macromolecules, 39, 4276-4278.

Okuzaki, H. (2006). Nanofibers of functional polymers fabricated by electrospinning, Kobunshi, 55, 126-129.

Okuzaki, H.; Takahashi, T.; Hara, Y. \& Yan, H. (2008). Uniaxially aligned carbon nanofibers derived from electrospun precursor yarns, J. Polym. Sci., Polym. Phys., 46, 305-310.

Okuzaki, H.; Takahashi, T.; Hara, Y. \& Yan, H. (2008). Conducting nanofiber yarns fabricated by electrospinning, Sen'i Gakkaishi, 64, 1, 5-10.

Park, S. H.; Kim, C.; Choi, Y. O. \& Yang, K. S. (2003). Preparations of pitch-based CF/ACF webs by electrospinning, Carbon, 41, 2655-2657.

Ren, Z. F.; Huang, Z. P.; Xu, J. H.; Bush, P.; Siegal, M. P. \& Provencio, P. N. (1998). Synthesis of large arrays of well-alighned carbon nanotubes on glass, Science, 282, 1105.

Reneker, D. H. \& Chun, I. (1996). Nanometre diameter fibres of polymer, produced by electrospinning, Nanotechnology, 7, 216-223.

Sariciftci, N. S.; Braun, D.; Zhang, C.; Srdanov, V. I.; Heeger, A. J.; Stucky, G. \& Wudl, F. (1993). Semiconducting polymer-buckminsterfullerene heterojunctions: Diodes, photodiodes, and photovoltaic cells, Appl. Phys. Lett., 62, 585.

Tuinstra, F. \& Koenig, J. L. (1970). Raman spectrum of graphite, J. Chem. Phys., 53, 1126.

Wang, Y.; Serrano, S. \& Santiago-Aviles, J. J. (2003). Raman characterization of carbon nanofibers prepared using electrospinning, Synth. Met., 138, 423-427.

Yang, S.; Lozano, K.; Lomeli, A.; Foltz, H. D. \& Jones, R. (2005). Electromagnetic interference shielding effectiveness of carbon nanofiber/LCP composites, Composites: Part A, 36, 691-697. 


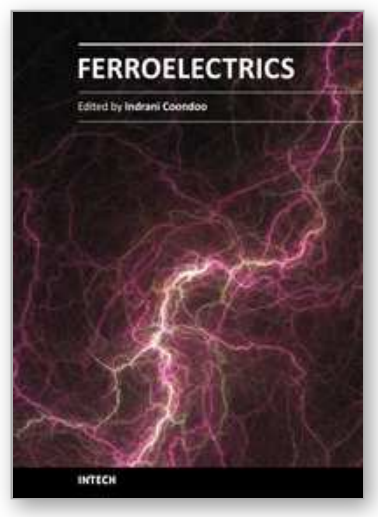

\author{
Ferroelectrics \\ Edited by Dr Indrani Coondoo
}

ISBN 978-953-307-439-9

Hard cover, 450 pages

Publisher InTech

Published online 14, December, 2010

Published in print edition December, 2010

Ferroelectric materials exhibit a wide spectrum of functional properties, including switchable polarization, piezoelectricity, high non-linear optical activity, pyroelectricity, and non-linear dielectric behaviour. These properties are crucial for application in electronic devices such as sensors, microactuators, infrared detectors, microwave phase filters and, non-volatile memories. This unique combination of properties of ferroelectric materials has attracted researchers and engineers for a long time. This book reviews a wide range of diverse topics related to the phenomenon of ferroelectricity (in the bulk as well as thin film form) and provides a forum for scientists, engineers, and students working in this field. The present book containing 24 chapters is a result of contributions of experts from international scientific community working in different aspects of ferroelectricity related to experimental and theoretical work aimed at the understanding of ferroelectricity and their utilization in devices. It provides an up-to-date insightful coverage to the recent advances in the synthesis, characterization, functional properties and potential device applications in specialized areas.

\title{
How to reference
}

In order to correctly reference this scholarly work, feel free to copy and paste the following:

Hidenori Okuzaki and Hu Yan (2010). Uniaxially Aligned Poly(p-phenylene vinylene) and Carbon Nanofiber Yarns through Electrospinning of a Precursor, Ferroelectrics, Dr Indrani Coondoo (Ed.), ISBN: 978-953-307439-9, InTech, Available from: http://www.intechopen.com/books/ferroelectrics/uniaxially-aligned-poly-pphenylenevinylene-and-carbon-nanofiber-yarns-through-electrospinning-of-a-

\section{INTECH}

open science | open minds

\section{InTech Europe}

University Campus STeP Ri

Slavka Krautzeka 83/A

51000 Rijeka, Croatia

Phone: +385 (51) 770447

Fax: +385 (51) 686166

www.intechopen.com

\section{InTech China}

Unit 405, Office Block, Hotel Equatorial Shanghai

No.65, Yan An Road (West), Shanghai, 200040, China

中国上海市延安西路65号上海国际贵都大饭店办公楼 405 单元

Phone: +86-21-62489820

Fax: +86-21-62489821 
(C) 2010 The Author(s). Licensee IntechOpen. This chapter is distributed under the terms of the Creative Commons Attribution-NonCommercialShareAlike-3.0 License, which permits use, distribution and reproduction for non-commercial purposes, provided the original is properly cited and derivative works building on this content are distributed under the same license. 